\title{
PERINDOPRIL ARGININE, INDAPAMIDE, AND AMLODIPINE FIXED DOSE COMBINATION INDUCED GINGIVAL OVERGROWTH: TWO CASES WITH SPECIFIC CLINICAL PRESENTATION
}

\author{
Melda Pelin AKKITAP ${ }^{1}$, Birsay GUMRU ${ }^{1 *}$, Omer Birkan AGRALI' ${ }^{2}$, Selin BABALI ${ }^{2}$ \\ ${ }^{1}$ Marmara University, Faculty of Dentistry, Department of Oral and Maxillofacial Radiology, 34854, Istanbul, Turkey \\ ${ }_{2}^{2}$ Marmara University, Faculty of Dentistry, Department of Periodontology, 34854, Istanbul, Turkey
}

\begin{abstract}
Drug induced gingival overgrowth (DIGO) is a frequent adverse effect of systemic medications. Amlodipine, although accepted as a safe antihypertensive drug due to its longer duration of action with lower dose and fewer adverse reactions compared to other antihypertensive agents, is among the causative drugs. As the aetiology of hypertension is multifactorial, a fixed dose combination containing amlodipine and other antihypertensive agents is currently preferred by physicians as a new treatment approach. The aim of this article is to report two cases of perindopril arginine, indapamide, and amlodipine fixed dose combination induced gingival overgrowth with an emphasis on the specific clinical presentation. Intraoral examination revealed poor oral hygiene, excessive dental plaque accumulation, and erythematous, oedematous, lobulated, enlarged marginal and interdental gingivae prone to bleeding. It was noteworthy that a red band appearance was present on the enlarged labial marginal gingivae in the patients. One month after the drug substitution, proper oral hygiene education and plaque control, and non-surgical periodontal treatment, a marked regression in DIGO and accompanying inflammatory symptoms were observed. Medical and dental practitioners should be aware that antihypertensive drugs used alone or in combination with other agents have the potential to cause gingival overgrowth.
\end{abstract}

Keywords: Fixed dose combination, Amlodipine, Gingival overgrowth

\begin{tabular}{|c|c|c|}
\hline \multicolumn{3}{|c|}{$\begin{array}{l}\text { *Corresponding author: Marmara University, Faculty of Dentistry, Department of Oral and Maxillo } \\
\text { E mail: bgumru@marmara.edu.tr (B. GUMRU) }\end{array}$} \\
\hline Melda Pelin AKKITAP & (iD) https://orcid.org/0000-0001-7744-6615 & Received: May 27, 2021 \\
\hline Birsay GUMRU & https://orcid.org/0000-0002-7734-4755 & Accepted: August 08, 2021 \\
\hline Omer Birkan AGRALI & https://orcid.org/0000-0003-4472-8370 & Published: January 01, 2022 \\
\hline Selin BABALI & (iD) https://orcid.org/0000-0001-8211-4906 & \\
\hline
\end{tabular}

\section{Introduction}

Drug induced gingival overgrowth (DIGO) is referred as abnormal growth of the gingival tissues, a secondary effect related to the use of a systemic medication (Biswas et al., 2017). Gingival overgrowth was previously termed as gingival hyperplasia or hypertrophy, which do not obviously reflect the histomorphological alteration of the pharmacologically affected gingiva, because the overgrowth is characterized by the increased production of extracellular ground substances resulting from increase in glycosaminoglycan, collagen, and active fibroblasts rather than an increase in cell number and/or volume (Trackman and Kantarci, 2015).

DIGO was reported for the first time by Kimball in 1939 due to long-term use of the antiepileptic drug phenytoin (Kimball, 1939). Currently, drugs associated with gingival overgrowth are classified in 3 main groups: anticonvulsants (phenytoin, sodium valproate, phenobarbitone, vigabatrin, primidone, ethosuximide, topiramate, and lamotrigine), calcium channel blockers (CCBs) (diltiazem, nifedipine, amlodipine, felodipine, nisoldipine, verapamil, nicardipine, nitrendipine, and oxodipine), and immunosuppressants (cyclosporine, tacrolimus, sirolimus) (Seymour et al., 1996). Rare cases of erythromycin, trimethoprim sulfamethoxazole, and oral contraceptive induced gingival overgrowth are also reported (Valsecchi and Cainelli, 1992; Caron et al., 1997; Mahajan and Sood, 2017). The prevalence of DIGO has been reported to be $10-50 \%$ for phenytoin, $8-70 \%$ for cyclosporine, and $5-80 \%$ for CCBs (Ellis et al., 1999; Koirala et al., 2017).

CCBs show their activity by blocking voltage-dependent calcium channels and inhibiting calcium ion influx across the membranes of cardiac and smooth muscle cells and are widely used in the treatment of cardiovascular diseases such as hypertension, angina pectoris, cardiac arrhythmias, and coronary artery spasms. Based on their chemical composition, they are divided into 2 groups as dihydropyridines (nifedipine, amlodipine, felodipine, isradipine, nicardipine, nitrendipine, oxodipine, nimodipine, and nisoldipine) and nondihydropyridines composed of phenylalkylamines (verapamil, gallopamil), benzothiazepines (diltiazem), and phenylpiperazines (flunarizine) (Toyo-Oka and Nayler, 1996; Godfraind, 
2014).

Amlodipine, one of the dihydropyridine CCBs, is frequently preferred for the management of hypertension due to its longer duration of action and fewer adverse effects compared to other CCBs (Valcárcel et al., 2006). The aetiology of hypertension is based on multiple factors such as increased circulatory volume, total peripheral vascular resistance, and abnormal high renin-angiotensin-aldosterone system activity. Largescale international studies have demonstrated that combination therapy, containing two to three antihypertensive agents acting on different targets, is necessary to effectively control the blood pressure (Ábrahám and Dézsi, 2017). Therefore, many fixed dose combinations containing amlodipine as a CCB have been produced and used in the management of hypertension. The prevalence of amlodipine induced gingival overgrowth has been reported to be much lower (1.7$3.3 \%$ ) in comparison to nifedipine (20-83\%) (Barclay et al., 1992; Jorgensen, 1997; Ellis et al., 1999). However, the pooled data in a recent review revealed increased rate of gingival overgrowth $(26.7 \%)$ among subjects on amlodipine (Gaur and Agnihotri, 2018).

The aim of this study is to present the specific clinical presentation and treatment approach of perindopril arginine, indapamide, and amlodipine fixed dose combination induced gingival overgrowth in two hypertensive patients.

\section{Case Presentations}

\subsection{Case 1}

A 65-year-old female patient admitted to the Department of Oral and Maxillofacial Radiology, Faculty of Dentistry, Marmara University, Istanbul, Turkey, with the complaint of red, swollen, and bleeding gingivae. Her medical history revealed hypertension that was controlled with perindopril arginine, indapamide, and amlodipine (10 $\mathrm{mg} / 2.5 \mathrm{mg} / 10 \mathrm{mg}$ ) fixed dose combination therapy for 6 months.

Intraoral examination revealed gingival overgrowth involving marginal gingivae and interdental papillae except the edentulous maxilla and edentulous mandibular left posterior region. Prominent red band appearance was observed on labial gingival margin of teeth \#43, 46, and 47. The gingival overgrowth and accompanying inflammatory symptoms were more severe around the mentioned teeth in comparison to teeth \#33-42. Dental plaque accumulation in the mandibular posterior region was noted to be higher compared to the anterior region (Figure 1a).

Following the substitution of the suspected drug with another antihypertensive agent containing perindopril arginine and indapamide $(10 \mathrm{mg} / 2.5 \mathrm{mg})$ by the consulted physician, non-surgical periodontal treatment including scaling and root planning was performed. After a month, a significant improvement in the mandibular anterior region was achieved, but the labial gingivae of the teeth \#43, 46, and 47 was still slightly erythematous and oedematous, since the patient could not perform brushing in the posterior region as effectively as in the anterior region (Figure 1b).

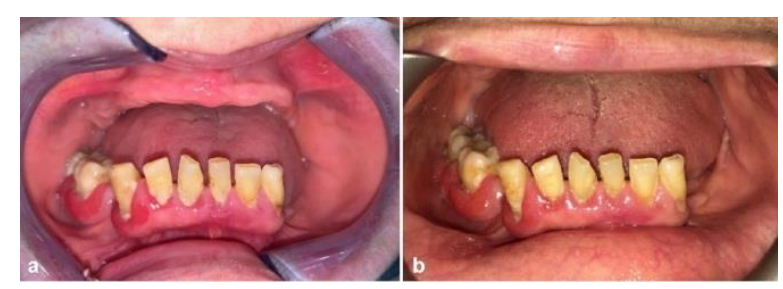

Figure 1. Initial intraoral view of Case 1 showing overgrowth of mandibular labial gingivae (a). One-month follow-up view showing the regression in gingival overgrowth following the substitution of the drug and non-surgical periodontal treatment (b).

\subsection{Case 2}

A 45-year-old male patient, who had been using perindopril arginine, indapamide, and amlodipine (10 $\mathrm{mg} / 2.5 \mathrm{mg} / 10 \mathrm{mg}$ ) fixed dose combination for 2 years, admitted to our clinic with complaints of generalized gingival swelling with bleeding during brushing in addition to halitosis. In intraoral examination, generalized marginal and interdental gingival overgrowth and red band appearance on the labial gingival margins were observed. The gingival tissues were erythematous, oedematous, lobulated, and prone to bleeding. Gingival recession due to plaque accumulation as a consequence of poor oral hygiene was observed (Figure 2a).

By consultation with the patient's physician, the suspected drug was substituted with another antihypertensive agent containing a combination of angiotensin converting enzyme inhibitor and thiazide derivative, ramipril and hydrochlorothiazide $(5 \mathrm{mg} / 25$ mg). Non-surgical periodontal treatment including scaling and root planning was performed. Regression in generalized gingival overgrowth was noticed after a month of drug substitution and proper plaque control. The red band appearance on labial gingival margin began to disappear but was not completely eliminated (Figure 2b).

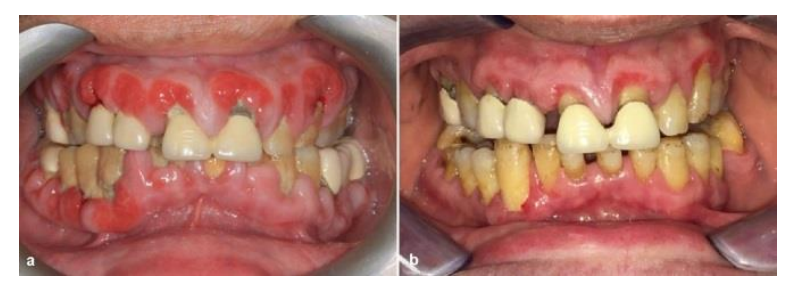

Figure 2. Initial intraoral view of Case 2 showing generalized gingival overgrowth (a). One-month followup view showing the regression in gingival overgrowth following the substitution of the drug and non-surgical periodontal treatment (b). 


\section{Black Sea Journal of Health Science}

\section{Results and Discussion}

A multifactorial model explaining the pathogenesis of DIGO was reported by Seymour et al. for the first time in 1996 (Seymour et al., 1996). Although the pathogenesis of DIGO has not yet been fully disclosed, oral hygiene, dose and duration of therapy, concentration of drug in body fluids, concomitant medications, age, gender, genetic predisposition, growth factors, and cytokines may be regarded as essential risk factors (Barclay et al., 1992; Seymour et al., 2000; Trackman and Kantarci, 2015).

Oral hygiene is a major risk factor in the development and clinical presentation of DIGO (Barclay et al., 1992; Hallmon and Rossmann, 1999; Lauritano et al., 2019). Although a clear synergistic relationship has not been outlined yet, evidence shows that poor plaque control and presence of gingival inflammation can exacerbate DIGO independently from the effect of the drug used (Seymour et al., 1996). However, there are studies reporting that there is no relationship between gingival changes and plaque scores and DIGO may occur even in patients with good oral hygiene (Barclay et al., 1992; Jorgensen, 1997).

The dose, duration of therapy, and concentration of drug in plasma, gingival crevicular fluid, and saliva are found to be directly related to the severity of DIGO (Hallmon and Rossmann, 1999; Gaur and Agnihotri, 2018). The average daily amlodipine dose causing gingival overgrowth varies between $2.5-10 \mathrm{mg}$, but it is noteworthy that the dose is reported to be $5 \mathrm{mg} /$ day in most case reports (James et al., 2000; Meisel et al., 2006; Gopal et al., 2015; Gaur and Agnihotri, 2018). However, there are also studies reporting that a dose of $5 \mathrm{mg} /$ day did not cause gingival overgrowth and a dose of $10 \mathrm{mg} /$ day caused more severe gingival overgrowth (Jorgensen, 1997; Arunachalam and Rao, 2013). Some authors failed to find a significant relationship between the amlodipine dose and the severity of gingival overgrowth and suggested that the dose based on the patient's body weight was important in the effect on the gingival tissue (Seymour et al., 2000). Although the gingival concentration of amlodipine has been found to be 2-3 times higher than its plasma concentration, the role and importance of the amount of drug in body fluids in pathogenesis have not been proven yet (Özdemir et al., 2002).

Concomitant medications play an important role in DIGO incidence and severity. DIGO incidence in kidney transplant recipients was found to be $8 \%$ when cyclosporine was used alone and 51\% when cyclosporine and nifedipine were used in combination, and the use of a combination of cyclosporine and CCB in organ transplant recipients was reported to result in more severe gingival overgrowth compared to the use of either drug alone (Thomason et al., 1996; James et al., 2000). On the other hand, the combined use of cyclosporine and azathioprine or prednisolone has been reported to reduce the severity of gingival overgrowth and long-term concomitant use of phenytoin and other anticonvulsants has been reported not to affect the severity (Hallmon and Rossmann, 1999). Age may significantly affect the severity of DIGO, and the severity of gingival overgrowth in childhood and adolescence is higher due to growth hormone and high fibroblast metabolism (Hassell and Hefti, 1991). Since phenytoin is usually prescribed for patients younger than 25 years, and cyclosporine for all ages, age has been reported as a risk factor for phenytoin and cyclosporine induced gingival overgrowth (Ellis et al., 1999). However, age may not be considered a risk factor for CCBs because these drugs are generally used in middle-aged and older adults (Gopal et al., 2015; Biswas et al., 2017; Gaur and Agnihotri, 2018). DIGO affects men more frequently than women with a ratio of 3.3:1, explained by the effect of androgen metabolism on fibroblast synthesis (Seymour et al., 2000; Livada and Shiloah, 2014; Lauritano et al., 2019).

Genetically, fibroblast heterogeneity has a determining effect on the response of the gingival tissues to the drug that can induce gingival overgrowth (DongariBagtzoglou, 2004; Livada and Shiloah, 2014). Studies have reported that DIGO is more severe in patients expressing HLA-DR2 or HLA-B37, while HLA-DR1 provides some degree of protection (Hallmon and Rossmann, 1999). It has also been suggested that MDR1 gene polymorphisms may change the inflammatory response to the drug due to the alteration in the tissue remodelling equilibrium induced by cytokines (Meisel et al., 2006). In addition, the polymorphism of hepatic cytochrome $\mathrm{P} 450$ enzymes responsible for the metabolism of CCBs causes the serum and tissue concentrations of CCBs differ among individuals (Thomason et al., 1996; Seymour et al., 2000; Livada and Shiloah, 2014).

Growth factors and cytokines have a potent stimulatory effect on migration, mitogenesis, and proliferation of fibroblasts and production of extracellular matrix associated with induction of the gingival overgrowth. Drugs associated with gingival overgrowth may interact with the pre-inflamed gingival tissue leading to an increase in specific growth factor and cytokine levels, so a synergistic increase in collagenous protein synthesis occurs (Dongari-Bagtzoglou, 2004; Biswas et al., 2017).

DIGO mostly affects the labial gingival surfaces in the maxillary/mandibular anterior regions (Hallmon and Rossmann et al., 1999; Agrawal, 2015). DIGO appears in the interdental papillae within the first 1-3 months following the onset of the drug, and the lesions involving the marginal gingivae and the papillae may merge and extend to the coronal part of the teeth in 12 months causing phonation, mastication, and aesthetic problems (Dongari-Bagtzoglou, 2004). The gingiva is erythematous, oedematous, and prone to bleeding in presence of inflammation, whereas it is pale pink, nodular, and fibrotic in the absence of inflammation (Agrawal, 2015). Although DIGO generally does not affect edentulous areas and disappears with extraction of teeth 
in the affected area, studies reporting DIGO around implants and under ill-fitting dentures exist (McCord et al., 1992; Khan et al., 2012).

Acute/chronic inflammatory overgrowths, idiopathic/familial/hereditary gingival overgrowths, neoplastic enlargements or gingival tumours, and gingival overgrowths due to systemic diseases (such as leukemia, sarcoidosis, and tuberculosis) should be considered in clinical differential diagnosis (Agrawal, 2015).

The first step in the treatment of DIGO involves drug substitution by consultation with the patient's physician. Discontinuation of the causative drug facilitates regression of DIGO within 1-8 weeks (Seymour et al., 1996). Mechanical and chemical plaque control and oral hygiene measures promote the reduction in the severity of DIGO and accelerate the healing process (Hallmon and Rossmann, 1999). If these measures are not effective, oral hygiene or function is adversely affected, or if the condition of the gingival tissue after treatment does not satisfy the patient aesthetically, surgical procedures (gingivectomy, gingivoplasty, flap surgery, electrosurgery, and laser surgery) are recommended (Hallmon and Rossmann, 1999).

The possibility of recurrence can be reduced by providing adequate plaque control, regular periodontal maintenance therapy, and periodic follow-ups (Hallmon and Rossmann, 1999; Ilgenli et al., 1999). In case the suspected drug is not substituted or is reintroduced, the recurrence may be inevitable even if the surgical procedure is performed and post-operative hygiene is ensured (Livada and Shiloah, 2014). The recurrence rate of cyclosporine or nifedipine induced gingival overgrowth within the 18 months following the periodontal surgery was found to be approximately $40 \%$ if the drug was continued (Ilgenli et al., 1999).

In this study, two cases of perindopril arginine, indapamide, and amlodipine $(10 \mathrm{mg} / 2.5 \mathrm{mg} / 10 \mathrm{mg}$ ) fixed dose combination induced gingival overgrowth are presented. In general, complaints and intraoral presentation of the patients were consistent with the literature. The red band appearance present on the labial marginal gingivae of the patients was striking. Drug substitution, non-surgical periodontal treatment including scaling and root planning, and good plaque control resulted in regression of the DIGO as well as reduction in the pre-existing inflammatory symptoms.

\section{Conclusion}

Medical and dental practitioners should be aware that antihypertensive drugs used alone or in combination with other agents have the potential to cause development of gingival overgrowth. In the cases presented, perindopril arginine, indapamide, and amlodipine fixed dose combination induced gingival overgrowth has a specific clinical presentation as a red band appearance on labial gingival margin and differs from the clinical picture of previous cases of amlodipine induced gingival overgrowth. However, further studies are needed to support our observation.

\section{Author Contributions}

BG and MPA; contributed to study conception and design. MPA, OBA and SB; collaborated for patient management and data collection. BG and MPA; drafted the manuscript. All authors reviewed and approved the manuscript.

\section{Conflict of Interest}

The authors declare that there is no conflict of interest.

\section{Ethical Approval/Informed Consent}

Written an informed consent form was obtained from the patients for the case presentation and necessary information was given to the family.

\section{References}

Ábrahám G, Dézsi CA. 2017. The antihypertensive efficacy of the triple fixed combination of perindopril, indapamide, and amlodipine: The results of the PETRA study. Adv Ther, 34(7): 1753-1763.

Agrawal AA. 2015. Gingival enlargements: Differential diagnosis and review of literature. World J Clin Cases, 3(9): 779-788.

Arunachalam LT, Rao S. 2013. Immunolocalization of Bcl-2 oncoprotein in amlodipine-induced gingival overgrowth. Indian J Dent Res, 24(2): 255-260.

Barclay S, Thomason JM, Idle JR, Seymour RA. 1992. The incidence and severity of nifedipine-induced gingival overgrowth. J Clin Periodontol, 19(5): 311-314.

Biswas S, Saha A, Das AK, Nair V, Biswas D. 2017. Antihypertensive drug induced gingival enlargement - a case report. JODAGH, 10(1): 7-11.

Caron F, Meurice JC, Dore P, Perault MC, Breux JP, Patte F. 1997. Gingival hyperplasia: a new side effect associated with trimethoprim-sulfamethoxazole (TML-SMX) treatment in pulmonary nocardiosis. Therapie, 52(1): 73-74.

Dongari-Bagtzoglou A; Research, Science and Therapy Committee, American Academy of Periodontology. 2004 Drug-associated gingival enlargement. J Periodontol, 75(10): 1424-1431.

Ellis JS, Seymour RA, Steele JG, Robertson P, Butler TJ, Thomason JM. 1999. Prevalence of gingival overgrowth induced by calcium channel blockers: a community-based study. J Periodontol, 70(1): 63-67.

Gaur S, Agnihotri R. 2018. Is dental plaque the only etiological factor in Amlodipine induced gingival overgrowth? A systematic review of evidence. J Clin Exp Dent, 10(6): e610e619.

Godfraind T. 2014. Calcium channel blockers in cardiovascular pharmacotherapy. J Cardiovasc Pharmacol Ther, 19(6): 501515.

Gopal S, Joseph R, Santhosh VC, Kumar VV, Joseph S, Shete AR. 2015. Prevalence of gingival overgrowth induced by antihypertensive drugs: A hospital-based study. J Indian Soc Periodontol, 19(3): 308-311.

Hallmon WW, Rossmann JA. 1999. The role of drugs in the pathogenesis of gingival overgrowth. A collective review of current concepts. Periodontol 2000, 21: 176-196.

Hassell TM, Hefti AF. 1991. Drug-induced gingival overgrowth: old problem, new problem. Crit Rev Oral Biol Med, 2(1): 103137. 
Ilgenli T, Atilla G, Baylas H. 1999. Effectiveness of periodontal therapy in patients with drug-induced gingival overgrowth. Long-term results. J Periodontol, 70(9): 967-972.

James JA, Marley JJ, Jamal S, Campbell BA, Short CD, Johnson RW, Hull PS, Spratt H, Irwin CR, Boomer S, Maxwell AP, Linden GJ. 2000. The calcium channel blocker used with cyclosporin has an effect on gingival overgrowth. J Clin Periodontol, 27(2): 109-115.

Jorgensen MG. 1997. Prevalence of amlodipine-related gingival hyperplasia. J Periodontol, 68(7): 676-678.

Khan S, Mittal A, Kanteshwari IK. 2012. Amlodipine induced gingival overgrowth: a case report. NJDSR, 1: 65-69.

Kimball OP. 1939. The treatment of epilepsy with sodium diphenyl hydantoinate. JAMA, 112(13): 1244-1245.

Koirala PK, Pradhan S, Gorkhali RS. 2017. Gingival enlargement management in a hospital - a case series. J Nepal Soc Perio Oral Implantol, 1(2): 84-90.

Lauritano D, Martinelli M, Baj A, Beltramini G, Candotto V, Ruggiero F, Palmieri A. 2019. Drug-induced gingival hyperplasia: An in vitro study using amlodipine and human gingival fibroblasts. Int J Immunopathol Pharmacol, 33: 2058738419827746.

Livada R, Shiloah J. 2014. Calcium channel blocker-induced gingival enlargement. J Hum Hypertens, 28(1): 10-14.

Mahajan A, Sood R. 2017. Case report: Oral contraceptives induced gingival overgrowth - a clinical case report. POJ Dent Oral Care, 1(1): 1-5.

McCord JF, Sloan P, Quayle AA, Hussey DJ. 1992. Phenytoin hyperplasia occurring under complete dentures: a clinical report. J Prosthet Dent, 68(4): 569-572.
Meisel P, Giebel J, Kunert-Keil C, Dazert P, Kroemer HK, Kocher T. 2006. MDR1 gene polymorphisms and risk of gingival hyperplasia induced by calcium antagonists. Clin Pharmacol Ther, 79(1): 62-71.

Özdemir Ö, Soylu M, Kütük E. 2002. Gingiva hyperplasia due to amplodipine: Seldom or an easy-to-recover side-effect. Turk Kardiyol Dern Ars, 30: 273.

Seymour RA, Ellis JS, Thomason JM. 2000. Risk factors for druginduced gingival overgrowth. J Clin Periodontol, 27(4): 217223.

Seymour RA, Thomason JM, Ellis JS. 1996. The pathogenesis of drug-induced gingival overgrowth. J Clin Periodontol, 23(3 Pt 1): $165-175$.

Thomason JM, Seymour RA, Ellis JS, Kelly PJ, Parry G, Dark J, Wilkinson R, Ilde JR. 1996. Determinants of gingival overgrowth severity in organ transplant patients. An examination of the role of HLA phenotype. J Clin Periodontol, 23(7): 628-634.

Toyo-Oka T, Nayler WG. 1996. Third generation calcium entry blockers. Blood Press, 5(4): 206-208.

Trackman PC, Kantarci A. 2015. Molecular and clinical aspects of drug-induced gingival overgrowth. J Dental Res, 94(4): 540-546.

Valcárcel Y, Jiménez R, Hernández V, Arístegui R, Gil A; NOTA Study Group. 2006. Efficacy and safety of amlodipine: a comparative study of hypertensive patients treated at primary- and specialised-care centres. Clin Drug Investig, 26(3):125-133.

Valsecchi R, Cainelli T. 1992. Gingival hyperplasia induced by erythromycin. Acta Derm Venereol, $72(2): 157$. 